\title{
Comparative chemical analysis of army ant mandibular gland volatiles (Formicidae: Dorylinae)
}

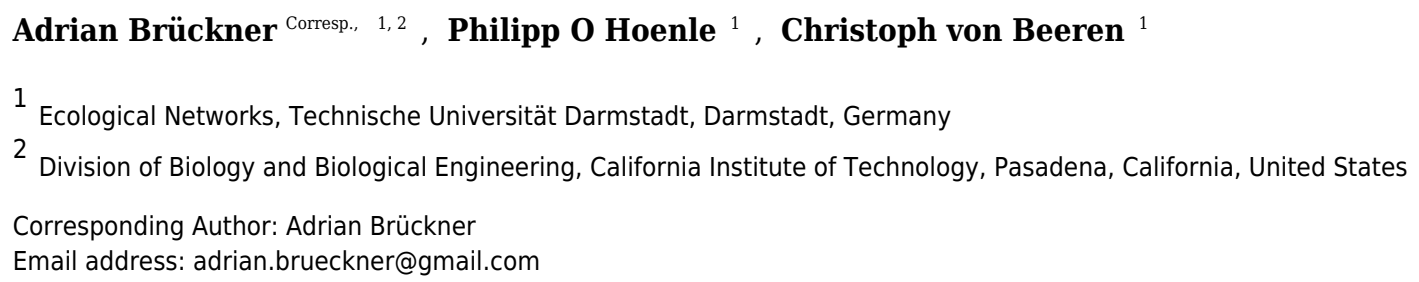

Army ants are keystone species in many tropical ecosystems. Yet, little is known about the chemical compounds involved in army ant communication. In the present study, we analyzed the volatile mandibular gland secretions - triggers of ant alarm responses - of six Neotropical army ant species of the genus Eciton (outgroup: Nomamyrmex esenbeckii). Using solid-phase microextraction, we identified 12 chemical compounds, primarily ketones with associated alcohols, one ester and skatole. Most compounds were shared among species, but their relative composition was significantly different. By comparing chemical distances of mandibular gland secretions to species divergence times, we showed that the secretions' compositions are not strictly determined by phylogeny. By identifying chemical bouquets of seven army ant species, our study provides a valuable comparative resource for future studies aiming to unveil the chemicals' precise role in army ant alarm communication. 


\section{Comparative chemical analysis of army ant mandibular gland volatiles}

\section{2 (Formicidae: Dorylinae)}

3 Adrian Brückner ${ }^{1,2^{*}}$, Philipp O. Hönle ${ }^{1}$ and Christoph von Beeren ${ }^{1 *}$

$4{ }^{1}$ Ecological Networks, Technische Universität Darmstadt, 64287 Darmstadt, Germany

$5 \quad{ }^{2}$ Division of Biology and Biological Engineering, California Institute of Technology, $1200 \mathrm{E}$

6 California Blvd, Pasadena, CA 91125, USA

7 *Corresponding authors: adrian.brueckner@gmail.com; cvonbeeren@gmail.com

\section{Abstract}

9 Army ants are keystone species in many tropical ecosystems. Yet, little is known about

10 the chemical compounds involved in army ant communication. In the present study, we analyzed

11 the volatile mandibular gland secretions - triggers of ant alarm responses - of six Neotropical

12 army ant species of the genus Eciton (outgroup: Nomamyrmex esenbeckii). Using solid-phase

13 microextraction, we identified 12 chemical compounds, primarily ketones with associated

14 alcohols, one ester and skatole. Most compounds were shared among species, but their relative

15 composition was significantly different. By comparing chemical distances of mandibular gland

16 secretions to species divergence times, we showed that the secretions' compositions are not

17 strictly determined by phylogeny. By identifying chemical bouquets of seven army ant species,

18 our study provides a valuable comparative resource for future studies aiming to unveil the

19 chemicals' precise role in army ant alarm communication. 
Introduction

Exocrine gland secretions play fundamental roles in interactions of arthropods with each other and with their environment (Eisner, 2003). Plenty of functions are known for these

27 secretions including venoms of scorpions or sugary exudates in ant-associated caterpillars

28 (Eisner, 2003). Particularly common are defensive secretions, which often are evolutionarily

29 conserved (Hefetz, 1993; but see Brand, 1978). Besides their role in repelling opponents,

30 defensive secretions in social insects often serve as alert signals to nestmates (e.g., formic acid in

31 formicine ants; Wilson \& Regnier, 1971). In contrast to these unspecific alarm-defense

32 compounds, many social insects additionally evolved specific alarm signals aiming to recruit

33 nestmates ("aggressive alarm” sensu Wilson \& Regnier, 1971). For instance, 'aggressive alarm'

34 pheromone blends of fungus-growing ants were mostly species-specific (Norman et al., 2017).

35 Supposedly, natural selection drives such aggressive alarm signals to diversify among sympatric

36 ant species (see Leonhardt et al., 2016; Wilson \& Regnier, 1971).

In ants, mandibular gland secretions generally contain alarm pheromones (Hölldobler \& Wilson, 1990; Wilson \& Regnier, 1971). In Eciton army ants, Brown (1959) observed that

39 crushed heads of $E$. hamatum majors stimulate an 'aggressive alarm' response resulting in 40 massive recruitment of workers and vigorous attacks, bites, and stings - a phenomenon we 41 similarly observed with various Eciton species (see also Torgerson \& Akre 1970). In contrast,

42 headless bodies evoked little or no response by passing army ants (Brown, 1959). Later, a study 43 by Torgerson \& Akre (1970) demonstrated that workers usually missed to show a typical alarm 
44 response when confronted with crushed major heads of allospecific army ant species, indicating

45 a certain level of pheromone specificity. Furthermore, a study by Lalor \& Hughes (2011)

46 indicated that 4-methylheptan-3-one might play an important role for the alarm behavior in $E$.

47 burchellii and E. hamatum. However, the response of workers towards comparatively large

48 amounts $(10 \mu 1)$ of the pure, synthetic ketone was weaker compared to the workers' response

49 towards crushed submajor heads (Lalor \& Hughes, 2011). We re-tested behavioral responses of

50 six Eciton species (including E. burchellii and E. hamatum workers) in laboratory nests at our

51 field site in Costa Rica towards high doses of 4-methylheptan-3-one (kindly provided by Stefan

52 Schulz, TU Braunschweig), which, however, elicited no pronounced response in workers. In

53 contrast, intracolonial trials with crushed major heads elicited strong excitement among colony

54 members and led to recruitment of major workers. These initial trials led us to re-evaluate the

55 mandibular gland secretions of Eciton army ants.

Additionally, we asked whether the ants' phylogenetic relationships determine their

mandibular gland chemistry. There are two principal ways in which pheromone blends can

evolve (Symonds \& Elgar 2008): (1) little and gradual differences in pheromone blends result in phylogenetic clustering (sensu Ivens et al. 2016), i.e. closely related species are also most similar

60 in their pheromone blends; (2) major 'saltational' shifts in pheromone composition results in

61 phylogenetic overdispersion (sensu Ivens et al. 2016), i.e. distantly related species are more

62 similar in their pheromonal blends than closely related species. To assess whether alarm

63 pheromones in army ants rather follow the first (gradual shifts) or the second mode (saltational

64 shifts) of pheromone evolution, we analyzed the volatile mandibular gland chemistry of six

65 sympatric species of Eciton army ants and one species of Nomamyrmex army ant. 

including large-bodied majors (Powell \& Franks, 2006). With their sharply-pointed, sickle-

69 shaped mandibles, the main task of majors is to defend the colony (Fig. 1A). Majors are known

70 to emit alarm pheromones from their mandibular glands when disturbed and therefore our study

71 focused on this particular caste (Brown, 1959). We collected majors of the army ant species

72 Eciton burchellii foreli Mayr 1886, E. dulcium crassinode Borgmeier 1955, E. hamatum

73 Fabricius 1781, E. lucanoides conquistador Weber 1949, E. mexicanum s. str. Roger 1863, and

E. vagans angustatum Roger 1863. Collections took place between 8:00 pm - 3:00 am in the tropical rainforest at La Selva Biological Station, Costa Rica (N10²5.847’ W8400.404’, altitude $67 \mathrm{~m}$ asl) in an area of $11 \mathrm{~km}^{2}$ from February to April 2017 . Voucher ant specimens are stored in absolute ethanol and deposited in CvB's personal collection.

We aimed to collect majors from various colonies of a given species. However, ensuring that army ant collections derive from different colonies is notoriously difficult when sampling over a period of several months in a restricted area due to the ants' migratory habit. Hence, resampling of the same colony might have occurred. Due to the high army ant population density at La Selva (O’Donnell et al. 2007), we presume that the majority of colonies were only sampled once. Overall, we collected majors from 4 collection events for E. burchellii, 2 collection events for E. dulcium, 2 collection events for E. lucanoides, 4 collection events for E. hamatum, 4 collection events for E. vagans, and 1 collection event for E. mexicanum (for a map of collection sites and collection dates see supplement S2). The army ant Nomamyrmex esenbeckii wilsoni

87 Santschi 1920 (1 collection event) served as outgroup. This species does not possess a distinct major caste and we thus collected the largest ant workers encountered during a single raid. 
90 were identified using the identification key of Longino (2010). Research and export permits were

91 issued and approved by the Ministry of the Environment, Energy and Technology of the

92 Republic of Costa Rica (MINAET; permit numbers: 192-2012-SINAC and R-009-2014-OT-

93 CONAGEBIO).

Chemical analyses of pheromone secretions. Major specimens for chemical analysis of mandibular gland contents were haphazardly chosen from the above-mentioned collections by taking majors from as many collection events as possible (see supplement S2). For each head space analysis, we used one ant head except for the smaller species E. mexicanum and $N$. esenbeckii where two heads were used. We analyzed five head space profiles per species in total except for E. mexicanum (4 head space samples corresponding to 8 major heads). Heads were removed from the rest of the body, crushed with forceps and placed in a $4 \mathrm{ml}$ glass vial which was immediately sealed with Parafilm ${ }^{\circledR}$ (Bemis NA, USA). Head crushing is a commonly used technique to liberate the volatile organic compounds (VOCs) produced in ants' mandibular glands and no chemical differences between crushed heads and dissected glands have been reported in Eciton and other ants (e.g., do Nascimento et al., 1993; Hughes et al., 2001; Keegans et al., 1993). We collected the gland's volatile organic compounds over a period of $30 \mathrm{~min}$ from the headspace of crushed heads using a solid-phase microextraction (SPME) fused silica fiber coated with $65 \mu \mathrm{m}$ polydimethylsiloxane/divinylbenzene (Supelco ${ }^{\circledR}$, Sigma-Aldrich, USA). Additionally, three air-blank controls were sampled with the same method to ensure that the detected compounds did not derive from any laboratory contamination. Chemical analyses were performed on a QP 2010ultra GC-MS (Shimadzu, Japan). For substance desorption we placed the SPME fiber in the injector port $\left(250^{\circ} \mathrm{C}\right)$ of the $\mathrm{GC}$ for 1 minute. The gas chromatograph was equipped with a ZB-5MS fused silica capillary column ( $30 \mathrm{~m} \times 0.25 \mathrm{~mm} \mathrm{ID}, \mathrm{df}=0.25 \mu \mathrm{m})$ from 
113 Phenomenex (USA). Hydrogen was used as carrier-gas with a constant flow rate of $3.1 \mathrm{ml} / \mathrm{min}$.

114 The temperature of the $\mathrm{GC}$ oven was raised from an initial $30^{\circ} \mathrm{C}$ for $1.5 \mathrm{~min}$, to $150^{\circ} \mathrm{C}$ with

$1157.5^{\circ} \mathrm{C} / \mathrm{min}$, followed by $10^{\circ} \mathrm{C} / \mathrm{min}$ to $250^{\circ} \mathrm{C}$ and a final isothermal hold at $250^{\circ} \mathrm{C}$ for $2 \mathrm{~min}$.

116 Electron ionization mass spectra were recorded at $70 \mathrm{eV}$ with ion source and transfer line

117 temperature of $230^{\circ} \mathrm{C}$ and $250^{\circ} \mathrm{C}$, respectively. Only compounds with an abundance $>1 \%$ across

118 samples were further considered. Compound were identified based on their mass spectra,

119 comparative database searches using the "Flavors and fragrances of natural and synthetic

120 compounds 2" (FFNSC2) (Mondello, 2011) and Wiley2009/NIST2011 databases and if possible

121 by comparison to authentic standards (see also results). The absolute stereochemical

122 configurations were not determined.

Statistics. As recently suggested by Junker (2018) we used a biosynthetically

124 informed distance matrix $\left(\mathrm{d}_{\mathrm{A}, \mathrm{B}}\right)$ to evaluate our data. Biosynthetically informed distances $\left(\mathrm{d}_{\mathrm{A}, \mathrm{B}}\right)$

125 are similar to generalized unique-fraction-metric distances (UniFrac) used in microbial ecology

126 (Chen et al., 2012; Lozupone \& Knight, 2005). Different from the semi-metric Bray-Curtis

127 similarity (Bray \& Curtis, 1957) that only incorporates information on the composition of a

128 community, UniFrac also considers the relative relatedness of the different community members

129 by weighting their reciprocal phylogenetic distances (Chen et al., 2012; Lozupone \& Knight,

130 2005). Yet, instead of including the bacterial phylogeny to community abundance data, the

131 approach suggested by Junker (2018) incorporates the enzymatic origin or substance classes (e.g.

132 aromatic, fatty acid, etc.) of compounds that co-occur in a complex blend with a specific relative

133 composition. This method corrects for the problem of biochemical relatedness. It thus partly

134 solves the problem that compounds of a compositional chemical dataset are dependent due to 135 shared biosynthetic pathways. Biosynthetically informed distances $\left(\mathrm{d}_{\mathrm{A}, \mathrm{B}}\right)$ require detailed 
136 knowledge about the enzymes involved. Often times, however, such information are not

137 available, because biosynthetic pathways of many compounds are still unresolved (Morgan,

138 2010). Thus, Junker (2018) also developed an alternative approach which allows to incorporate

139 chemical substance classes or other information such as compound chain length. Since no

140 enzymatic data on the mandibular gland compounds of army ants are available, we used the

141 alternative approach and used compound chain length as an additional information to calculate

142 the biosynthetically informed distance matrix. We used chain length because it more accurately

143 reflects the relationships between the studied compounds than compound classes. This is because

144 ketones and alcohols of the same chain length are directly linked by a simple redox reaction. As

145 suggested by Junker (2018), we merged this distance matrix with the conventional Bray-Curtis

146 matrix using the default settings (see Junker 2018 for a detailed outline, the R script, and R

147 functions). We used the $\mathrm{d}_{\mathrm{A}, \mathrm{B}}$ matrix to test for multivariate compositional differences with a

148 permutational multivariate analysis of variance (PERMANOVA), to test for homogeneity of

149 multivariate dispersions (PERMDISP), and to construct a non-metric multidimensional scaling

150 (NMDS) ordination plot. Vectors in the ordination space, which represent compounds

151 significantly contributing to data point separation, were fitted onto the NMDS plot as arrows,

152 using the envfit()-function in "vegan" (Oksanen et al., 2007). Significance of fitted vectors was

153 assessed using permutations $(n=10,000)$ and goodness of fit statistics (see Oksanen et al., 2007

154 and data supplement for details).

155 A well resolved phylogeny of Eciton was recently published (Winston et al., 2017), of

156 which we extracted the species divergence times. We used divergence times and $d_{A, B}$ values to

157 investigate whether mandibular gland chemistry reflects the species' phylogenetic history. For

158 this, we constructed two cluster dendrograms of the divergence time and the merged 
159 biosynthetically informed distance $\mathrm{d}_{\mathrm{A}, \mathrm{B}}$ using the tanglegram function as implemented in the $\mathrm{R}$

160 package "dendextend". The tanglegram structure was improved to maximum overlap of both

161 dendrograms by rotating the trees' nodes without changing their topology. Additionally, we

162 performed Mantel tests to analyze whether divergence time and chemical dissimilarity matrices

163 are correlated with each other. As chemical dissimilarity matrices we used: i) the merged

164 biosynthetically informed distance $\mathrm{d}_{\mathrm{A}, \mathrm{B}}$, ii) a Bray-Curtis dissimilarity matrix based on the mean

165 relative proportion of compounds with a different chain length (categories: C6-C11, C13), and

166 iii) a Bray-Curtis dissimilarity matrix based on the mean relative proportion of different

167 compound classes (i.e. alcohols, esters, ketones, indole). As we only correlated very small

168 matrices (seven species) with each other, the statistical power was comparatively low. All

169 analyses were performed with R 3.3.2 (R Core Team, 2017), using the R packages "ade4" (Dray

170 \& Dufour, 2007), “cluster” (Maechler et al., 2012), “dendextend” (Galili, 2015), “GUniFrac”

171 (Chen, 2012) and "vegan" (Oksanen et al., 2007).

\section{Results and Discussion}

Compared to the study of Keegans et al. (1993), our analyses revealed a more

174 complex chemical blend of mandibular gland VOCs in Eciton ants, which might be attributed to

175 the development of more enhanced chemical analytical techniques. We detected and identified

176 ten different VOCs from the mandibular glands of Eciton army ants and two additional ones

177 from N. esenbeckii (Table 1). The main compounds were characterized by a prominent $\mathrm{m} / \mathrm{z}=86$

178 or $m / z=59$ fragment (in ketones or alcohols, respectively). The $m / z=86$ indicated either 4-

179 ketones or 3-ketones with a methyl group in position 2 or 4 arising from a McLafferty

180 rearrangement of the carbon-oxygen double bond. This ion, the lack of a prominent $m / z=71$,

181 together with the base ion at $m / z=57$ arising from the $\alpha$-cleavage relative to the carbonyl C, 
182 indicated that the compounds are 4-methyl-3-ketones $(\mathbf{5}, \mathbf{7}, \mathbf{9}$; see Table 1 for compound IDs).

183 The identities of 4,6-dimethyl-3-ketones were evaluated based on mass spectrometric data

184 provided by Fales et al. (1980), Bestmann et al. (1988) and Bergmann et al. (2001).

185 Consequently, we assigned the detected alcohols based on their $\mathrm{M}^{+}-1$ ion to an affiliated ketone

186 that represented the oxidized form of a respective alcohol (see also do Nascimento et al., 1997).

187 Similarly, we identified the 2-ketone (prominent ion at $m / z=58$ again arising from a McLafferty

188 rearrangement) and 2-alcohol (base ion at $m / z=45$ representing a $\mathrm{CH}_{3}-\mathrm{CH}-\mathrm{OH}$ moiety) as

189 heptan-2-one (3) and heptan-2-ol (4), which are known glandular compounds of ants (see e.g.,

190 Blum et al., 1982; Scheffrahn et al., 1984). The identity of 4-methylheptan-3-one (5), 4-

191 methylheptan-3-ol (6), 2-methylpentan-1-ol (1), and 3-methyl-1H-indole (11; common name:

192 skatole) was additionally confirmed by authentic standards which were kindly provided by

193 Stefan Schulz (TU Braunschweig) or purchased from Sigma-Aldrich (St. Louis, USA). The ester

194 3-methylbutyl octanoate (12) was identified based on mass spectrometric data using the

195 procedure described in Brückner et al. (2015). Most of the detected ketones $(\mathbf{3}, \mathbf{5}, \mathbf{7}, \mathbf{9})$ and

196 alcohols $(\mathbf{1}, \mathbf{2}, \mathbf{4}, \mathbf{6}, \mathbf{8}, \mathbf{1 0})$ are common mandibular gland compounds of ants (Attygalle \&

197 Morgan, 1984). For instance, 4-methylheptan-3-one (5) and 4-methylheptan-3-ol (6), which were

198 found in all species studied here, were described as alarm pheromones of several ant species

199 including E. burchellii (Keegans et al., 1993; Hölldobler \& Wilson, 1990). The same two

200 compounds are also described as defensive compounds in several arthropods, e.g. in opilionids

201 (Meinwald et al., 1971; Raspotnig, 2012).

202 Like in fungus-growing ants, army ant species had distinct mandibular gland chemical

203 profiles (PERMANOVA: $\mathrm{n}_{\text {perm }}=10,000, \mathrm{n}=33$, pseudo $\mathrm{F}=55.5, r^{2}=0.93, \mathrm{p}<0.001$ ), forming

204 idiosyncratic species clusters in the NMDS ordination plot (Fig. 1B; 2D-stress=0.06; Table 2). 
205 Yet, some species exhibited more variable alarm pheromone profiles than others (PERMDISP:

$\left.206 \mathrm{~F}_{6,27}=5.2, \mathrm{p}=0.001\right)$. For instance, profile variance was higher in E. burchellii and E. hamatum

207 compared to E. dulcium and E. lucanoides (Fig. 1B; Table 2). Interspecific differences in

208 mandibular gland VOCs were not strictly determined by army ant phylogeny (Fig. 2). Only for

209 E. burchellii and E. hamatum, we found that the closest relatives also possessed the closest

210 similarity in mandibular gland VOCs (Fig. 2), with some E. burchellii headspace samples falling

211 within the E. hamatum cluster (supplement S1). Interestingly, when tested against four

212 allospecific army ant species, Torgerson \& Akre (1970) observed that only E. burchellii crushed

213 heads elicited a typical alarm response in E. hamatum workers. For all other Eciton species, the

214 topologies of the two dendrograms, i.e. species divergence times and biosynthetically informed

215 distances, were incongruent (Fig. 2) and not correlated (Mantel test on Spearman's rank

216 correlation: $\left.\rho_{\mathrm{s}}=-0.21, \mathrm{p}=0.78\right)$. Further chemical characters like the chain lengths or compound

217 classes of chemicals found in the mandibular gland were also not correlated to the divergence

218 times (Mantel tests on Spearman's rank correlation: compound chain length: $\rho_{\mathrm{s}}=-0.24, \mathrm{p}=0.80$;

219 compound classes: $\left.\rho_{\mathrm{s}}=-0.29, \mathrm{p}=0.87\right)$. The incongruent dendrogram topologies together with a

220 non-significant Mantel tests provide evidence that alarm pheromone blends are not determined

221 by phylogeny. Pheromone evolution in Eciton army ants seems to follow a "saltational mode of

222 evolution" expressed by a pattern of phylogenetic overdispersion (Baker 2002; Roelofs et al.

223 2002; Symonds \& Elgar 2008), rather than evolving via small gradual changes in pheromone

224 composition which would most likely result in phylogenetic clustering.

The saltational mode of pheromone evolution leads to distinct pheromone blends among

226 closest relatives, and thus possibly reduces or prevents interspecific responses to pheromones

227 (e.g., bark beetles: Symonds \& Elgar 2004; ermine moths: Löfstedt et al. 1991; ants: Torgerson 
228 \& Akre 1970; van Wilgenburg et al. 2011; Menzel et al. 2017a). This pattern was now detected

229 for alarm pheromone blends in two of the most prominent ant groups of tropical rainforests, i.e.

230 fungus-growing ants (Norman et al., 2017) and army ants. It remains to be confirmed whether

231 this is a universal pattern in communities of closely related ants. For social insect alarm

232 pheromones in general, Leonhardt et al. (2016) suggested that natural selection acts on

233 pheromone diversification and maintenance and thus ecological rather than phylogenetic effects

234 are expected to shape alarm pheromone blends in co-occurring ant species (see also Menzel et al.

235 2017b). The ultimate mechanism of alarm pheromone diversification in ants (e.g., selection

236 against interspecific cross-activity) remains unknown and calls for further investigation.

\section{Conclusion}

The exact nature of alarm pheromone communication in army ants and the underlying

mechanism of pheromone diversification are still poorly understood. Conclusive bioassays using

more complex blends-as described here - and tests with more realistic pheromone

241 concentrations are needed to better understand which chemical compounds of the mandibular

242 gland bouquet are in fact relevant in army ant alarm communication. By providing details about

243 the glands' chemical blends, the present study provides a valuable resource for such future

244 studies.

\section{Acknowledgments}

We thank Bryan Ospina for his assistance in the field, Adrian Pinto, Carlos de la Rosa,

247 Bernal Matarrita Carranza, and the entire staff of La Selva Biological Station for their generous

248 support. We are also grateful to Günther Raspotnig for his advice on compound identification, 
249 Stefan Schulz for providing authentic standards, as well as two anonymous reviewers for 250 valuable comments. 


\section{References}

253 Attygalle AB, and Morgan ED. 1984. Chemicals from the glands of ants. Chemical Society

254 Reviews 13:245-278.

255 Baker TC. 2002. Mechanism for saltational shifts in pheromone communication systems.

256 Proceedings of the National Academy of Sciences 99: 13368-13370.

257 Bergmann J, Löfstedt C, Ivanov VD, and Francke W. 2001. Identification and assignment of

258 the absolute configuration of biologically active methyl-branched ketones from Limnephilid 259 caddis flies. European Journal of Organic Chemistry 2001:3175-3179.

260 Bestmann HJ, Attygalle AB, Glasbrenner J, Riemer R, Vostrowsky O, Constantino MG,

261 Melikian G, and Morgan ED. 1988. Pheromones, 65. Identification of the volatile components

262 of the mandibular gland secretion of the ant Manica rubida: Structure elucidation, synthesis, and 263 absolute configuration of Manicone. European Journal of Organic Chemistry 1988:55-60.

264 Blum MS, Jones TH, Snelling RR, Overal WL, Fales HM, and Highet RJ. 1982. Systematic

265 implications of the exocrine chemistry of some Hypoclinea species. Biochemical Systematics and 266 Ecology 10:91-94.

267 Bray JR, and Curtis JT. 1957. An ordination of the upland forest communities of southern

268 Wisconsin. Ecological Monographs 27:325-349.

269 Brand JM. 1978. Fire ant venom alkaloids: their contribution to chemosystematics and 270 biochemical evolution. Biochemical Systematics and Ecology 6:337-340. 
271 Brown WL. 1959. The release of alarm and attack behavior in some New World army ants.

272 Psyche: A Journal of Entomology 66:25-27.

273 Brückner A, Stabentheiner E, Leis HJ, and Raspotnig G. 2015. Chemical basis of

274 unwettability in Liacaridae (Acari, Oribatida): specific variations of a cuticular acid/ester-based 275 system. Experimental and Applied Acarology 66:313-335.

276 Chen J. 2012. GUniFrac: generalized UniFrac distances. R package version 1:2012.

277 Chen J, Bittinger K, Charlson ES, Hoffmann C, Lewis J, Wu GD, Collman RG, Bushman

278 FD, and Li H. 2012. Associating microbiome composition with environmental covariates using 279 generalized UniFrac distances. Bioinformatics 28:2106-2113.

do Nascimento RR, Jackson BD, Morgan ED, Clark WH, and Blom PE. 1993. Chemical

281 secretions of two sympatric harvester ants, Pogonomyrmex salinus and Messor lobognathus.

282 Journal of Chemical Ecology 19:1993-2005.

283 do Nascimento RR, Morgan ED, König W, and Della Lucia TM. 1997. Absolute

284 configuration of 4-methyl-3-heptanone and 4-methyl-3-heptanol from mandibular glands of

285 virgin males and females of Atta sexdens rubropilosa. Journal of Chemical Ecology 23:15692861575.

287 Dray S, and Dufour A-B. 2007. The ade4 package: implementing the duality diagram for 288 ecologists. Journal of Statistical Software 22:1-20.

289 Eisner T. 2003. For love of insects. Harvard University Press, Cambridge, MA.

290 Fales H, Jaouni T, Schmidt J, and Blum M. 1980. Mandibular gland allomones of Dasymutilla 291 occidentalis and other mutillid wasps. Journal of Chemical Ecology 6:895-903. 
292 Galili T. 2015. dendextend: an R package for visualizing, adjusting and comparing trees of

293 hierarchical clustering. Bioinformatics 31:3718-3720.

294 Hefetz A. 1993. Hymenopteran exocrine secretions as a tool for chemosystematic analysis:

295 possibilities and constraints. Biochemical Systematics and Ecology 21:163-169.

296 Hölldobler B, and Wilson EO. 1990. The ants: Harvard University Press.

297 Hughes WO, Howse PE, and Goulson D. 2001. Mandibular gland chemistry of grass-cutting

298 ants: species, caste, and colony variation. Journal of Chemical Ecology 27:109-124.

299 Ivens ABF, von Beeren C, Blüthgen N, Kronauer DJC. 2016. Studying the complex

300 communities of ants and their symbionts using ecological network analysis. Annual Reviews of

301 Entomology 61:353-371

302 Junker RR. 2018. A biosynthetically informed distance measure to compare secondary

303 metabolite profiles. Chemoecology 28:29-37.

304 Keegans SJ, Billen J, Morgan ED, and Gökcen OA. 1993. Volatile glandular secretions of

305 three species of new world army ants, Eciton burchelli, Labidus coecus, and Labidus praedator.

306 Journal of Chemical Ecology 19:2705-2719.

307 Lalor PF, and Hughes WO. 2011. Alarm behaviour in Eciton army ants. Physiological 308 Entomology 36:1-7.

309 Leonhardt SD, Menzel F, Nehring V, and Schmitt T. 2016. Ecology and evolution of

310 communication in social insects. Cell 164:1277-1287.

311 Longino J. 2010. Ants of Costa Rica. The Evergreen State College, Olympia, WA. 
312 Löfstedt C, Herrebout, WH. Menken SBJ. 1991. Sex pheromones and their potential role in

313 the evolution of reproductive isolation in small ermine moths (Yponomeutidae). Chemoecology

$3142: 20-28$.

315 Lozupone C, and Knight R. 2005. UniFrac: a new phylogenetic method for comparing

316 microbial communities. Applied and Environmental Microbiology 71:8228-8235.

317 Maechler M, Rousseeuw P, Struyf A, Hubert M, and Hornik K. 2012. Cluster: cluster

318 analysis basics and extensions. R package version 1:56.

319 Meinwald J, Kluge A, Carrel J, and Eisner T. 1971. Acyclic ketones in the defensive

320 secretion of a "daddy longlegs" (Leiobunum vittatum). Proceedings of the National Academy of

321 Sciences of the United States of America 68:1467-1468.

322 Mondello L. 2011. Ffnsc 2: Flavors and Fragrances of Natural and Synthetic Compounds, Mass

323 Spectral Database: John Wiley.

324 Menzel F, Schmitt T, Blaimer BB. 2017a. The evolution of a complex trait: cuticular

325 hydrocarbons in ants evolve independent from phylogenetic constraints. Journal of Evolutionary

326 Biology 30(7):1372-1385.

327 Menzel F, Blaimer BB, Schmidt T. 2017b. How do cuticular hydrocarbons evolve?

328 Physiological constraints and climatic and biotic selection pressures act on a complex functional

329 trait. Proceedings of the Royal Society B 284:20161727.

330 Morgan ED. 2010. Biosynthesis in Insects. Camebridge: RSC Publishing. 
331 Norman VC, Butterfield T, Drijfhout F, Tasman K, Hughes WO. 2017. Alarm pheromone

332 composition and behavioral activity in fungus-growing ants. Journal of Chemical Ecology

$333 \quad 43: 225-35$

334 O’Donnell S, Lattke J, Powell S, Kaspari M. 2007. Army ants in four forests: geographic

335 variation in raid rates and species composition. Journal of Animal Ecology 76:580-589.

336 Oksanen J, Kindt R, Legendre P, O’Hara B, Stevens MHH, Oksanen MJ, and Suggests M.

337 2007. The vegan package. Community ecology package 10:631-637.

338 Powell S, Franks NR. 2006. Ecology and the evolution of worker morphological diversity: a

339 comparative analysis with Eciton army ants. Functional Ecology 20:1105-1114.

340 Scheffrahn RH, Gaston LK, Sims JJ, and Rust MK. 1984. Defensive ecology of Forelius

341 foetidus and its chemosystematic relationship to F.(= Iridomyrmex) pruinosus (Hymenoptera:

342 Formicidae: Dolichoderinae). Environmental Entomology 13:1502-1506.

343 R Core Team. 2017. R: A language and environment for statistical computing. R Foundation for

344 Statistical Computing, Vienna, Austria. 2016.

345 Raspotnig G. 2012. Scent gland chemistry and chemosystematics in harvestmen. Biologia

346 Serbica 34:5-18.

347 Roelofs WL, Liu W, Hao G, Jiao H, Rooney AP, Linn CE. 2002. Evolution of moth sex

348 pheromones via ancestral genes. Proceedings of the National Academy of Sciences of the United

349 States of America 99:13621-13626.

350 Symonds MRE, Elgar MA. 2004. The mode of pheromone evolution: evidence from bark 351 beetles. Proceedings of the Royal Society London B 271:839-846. 
352 Symonds MRE, Elgar MA. 2008. The evolution of pheromone diversity. Trends in Ecology 353 and Evolution 23:220-228.

354 Wilson EO, and Regnier FE. 1971. The evolution of the alarm-defense system in the formicine 355 ants. The American Naturalist 105:279-289.

356 Winston ME, Kronauer DJ, and Moreau CS. 2017. Early and dynamic colonization of Central 357 America drives speciation in Neotropical army ants. Molecular Ecology 26:859-870. 
Figure 1 (on next page)

Eciton army ants and their mandibular gland compounds.

A: Eciton lucanoides major with sickle-shaped mandibles guarding the colony's emigration column (La Selva, Costa Rica). Photograph by Philipp O Hoenle. B: NMDS ordination plot depicting the distinct composition of mandibular gland profiles of different army ant species. Chemical compounds that significantly contributed to data separation are mapped onto the ordination as vectors; compound IDs correspond to Table 1. 


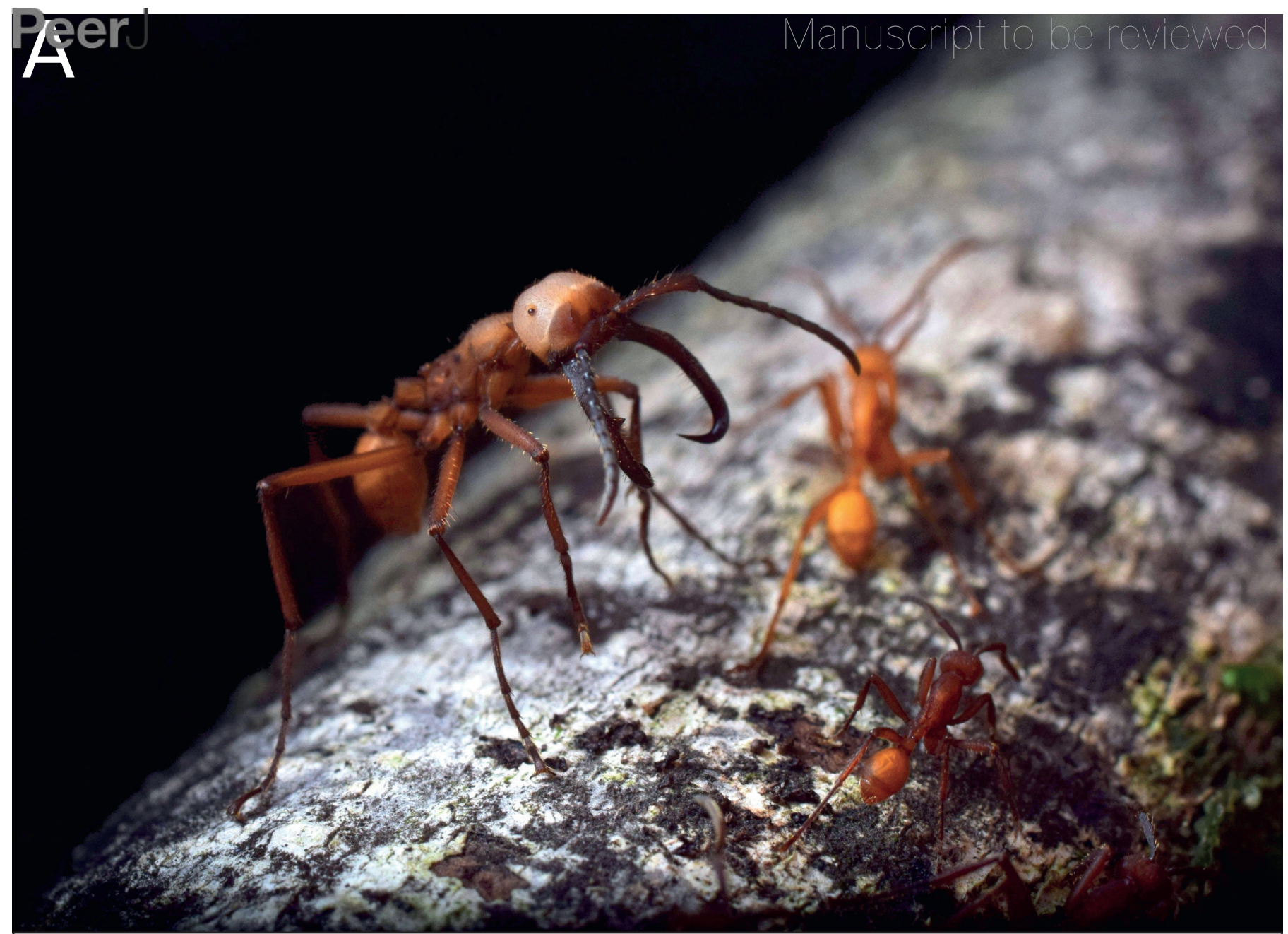

B

- N. esenbeckii wilsoni

* E. burchellii foreli

- E. dulcium crassinode

* E. hamatum

- E. lucanoides conquistador

- E. mexicanum s. str.

- E. vagans angustatum

$0^{0}$

(3)

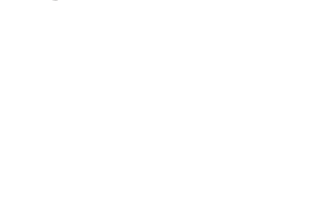

(1)

(5)

(1) $\mathrm{OH}$

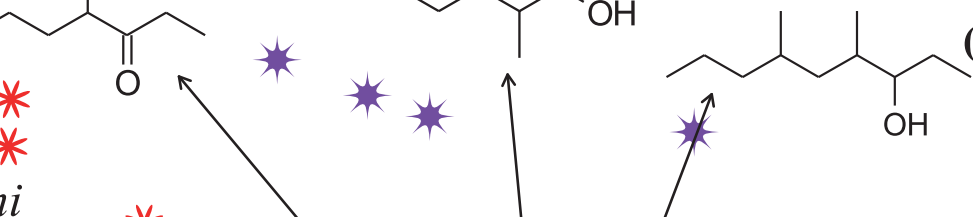

* 
Figure 2 (on next page)

A chemo-evolutionary scenario of Eciton army ants.

Dendrograms (based on unweighted averages) of species divergence times (extracted from Winston et al. 2017) and chemical distances of mandibular gland secretions. Colors correspond to Fig. 1. 


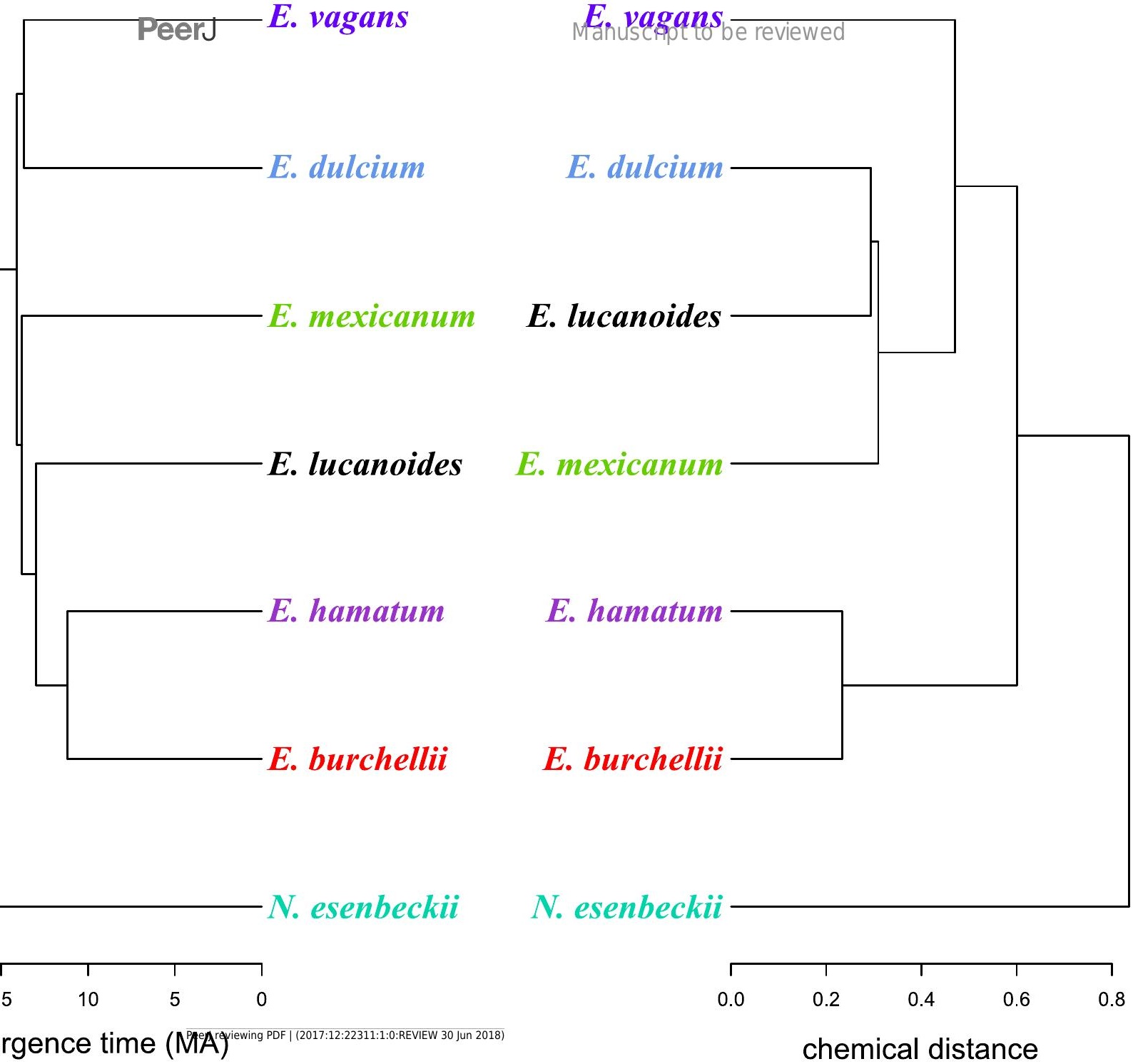




\section{Table $\mathbf{1}$ (on next page)}

Mass spectrometric data of volatiles organic compounds collected from the mandibular glands of army ants from the genus Eciton as well as Nomamyrmex esenbeckii. 


\begin{tabular}{|c|c|c|}
\hline $\begin{array}{l}\text { compound } \\
\text { ID }\end{array}$ & $\begin{array}{l}\text { mass spectrometric fragmentation } \mathrm{m} / z \\
(\text { relative intensity } \% \text { ) }\end{array}$ & identified as \\
\hline 1 & $\begin{array}{l}101\left(\mathbf{M}^{+}-\mathbf{1} ;<1\right), 84(6), 71(19), 70(18), 69(18), \\
57(7), 55(29), 43(100), 41(35)\end{array}$ & 2-methylpentan-1-ol \\
\hline 2 & $\begin{array}{l}115\left(\mathbf{M}^{+}-\mathbf{1} ;<1\right), 98(2), 69(19), 59(100), 58(24), \\
57(26), 45(35), 41(38)\end{array}$ & 4-methylhexan-3-ol \\
\hline 3 & $\begin{array}{l}114\left(\mathbf{M}^{+} ; 5\right), 99(3), 85(3), 71(15), 58(61), 55(7), \\
43(100), 41(13)\end{array}$ & heptan-2-one \\
\hline 4 & $\begin{array}{l}115\left(\mathbf{M}^{+}-1 ; 1\right), 101(4), 98(8), 83(9), 70(9), 55 \\
(25), 45(100), 41(13)\end{array}$ & heptan-2-ol \\
\hline 5 & $\begin{array}{l}128\left(\mathbf{M}^{+} ; 1\right), 99(6), 86(43), 71(63), 57(100), 55 \\
(13), 43(72), 41(19)\end{array}$ & 4-methylheptan-3-one \\
\hline 6 & $\begin{array}{l}129\left(\mathbf{M}^{+}-1 ;<1\right), 112(1), 101(9), 83(17), 70(8), \\
59(100), 55(24) 43(19), 41(24)\end{array}$ & 4-methylheptan-3-ol \\
\hline 7 & $\begin{array}{l}156\left(\mathbf{M}^{+} ;<1\right), 127(1), 99(5), 86(44), 69(3), 57 \\
(100), 55(6), 43(11), 41(14)\end{array}$ & 4,6-dimethyloctan-3-one \\
\hline 8 & $\begin{array}{l}157\left(\mathbf{M}^{+}-1 ;<1\right), 140(4), 129(8), 111(11), 98(7), \\
85(3), 83(4), 69(40), 59(100), 57(35), 55(22), \\
43(20), 41(28)\end{array}$ & 4,6-dimethyloctan-3-ol \\
\hline 9 & $\begin{array}{l}170\left(\mathbf{M}^{+} ; 1\right), 141(1), 127(1), 113(3), 99(6), 86 \\
(77), 71(43), 69(5), 57(100), 55(13), 43(51), 41 \\
(28)\end{array}$ & $\begin{array}{l}\text { 4,6-dimethylnonan-3- } \\
\text { one }\end{array}$ \\
\hline 10 & $\begin{array}{l}171\left(\mathbf{M}^{+}-\mathbf{1} ;<1\right), 154(1), 143(7), 125(3), 112(7), \\
99(1), 97(2), 85(10), 83(17), 69(35), 59(100), \\
58(28), 57(33), 55(25), 43(40), 41(26)\end{array}$ & 4,6-dimethylnonan-3-ol \\
\hline 11 & $\begin{array}{l}131\left(\mathbf{M}^{+}+1 ; 66\right), 130\left(\mathrm{M}^{+} ; 100\right), 103(10), 77(15), \\
51(7)\end{array}$ & 3-methyl-1H-indole \\
\hline 12 & $\begin{array}{l}214\left(\mathbf{M}^{+} ;<1\right), 171(1), 145(7), 144(4), 128(5), \\
127(51), 115(3), 101(5), 71(32), 70(100), 57 \\
(46), 55(36), 43(43), 41(27)\end{array}$ & 3-methylbutyl octanoate \\
\hline
\end{tabular}




\section{Table 2 (on next page)}

Proportions (mean $\pm \mathrm{SE}$ ) of volatile mandibular gland secretions of different army ant species.

Subspecies names are listed in materials and methods. Mean proportions and standard errors are based on the uncorrected integrated peak areas of the total ion chromatograms obtained via SPME-GC/MS (see Haberer et al. 2017). Compound IDs correspond to Table 1. 


\begin{tabular}{|c|c|c|c|c|c|c|c|}
\hline $\begin{array}{l}\text { compound } \\
\text { ID } \\
\end{array}$ & $\begin{array}{c}N . \\
\text { esenbeckii }\end{array}$ & $\begin{array}{c}E . \\
\text { burchellii }\end{array}$ & $\begin{array}{c}E . \\
\text { dulcium }\end{array}$ & $\begin{array}{c}E . \\
\text { hamatum }\end{array}$ & $\begin{array}{c}E . \\
\text { lucanoides }\end{array}$ & $\begin{array}{c}E . \\
\text { mexicanum }\end{array}$ & $\begin{array}{c}E . \\
\text { vagans }\end{array}$ \\
\hline 1 & - & - & - & $22.7 \pm 2.1$ & - & - & - \\
\hline 2 & - & $2.6 \pm 0.4$ & - & - & - & - & $14 \pm 0.9$ \\
\hline 3 & $60.1 \pm 1.5$ & - & - & - & - & - & - \\
\hline 4 & $8.8 \pm 0.5$ & - & - & - & - & - & - \\
\hline 5 & $22.6 \pm 0.3$ & $29.2 \pm 6.2$ & $0.9 \pm 0.2$ & $26.1 \pm 6$ & $4.7 \pm 0.6$ & $1.8 \pm 0.5$ & $8.7 \pm 0.5$ \\
\hline 6 & $8.5 \pm 1.3$ & $42.1 \pm 6.9$ & $4 \pm 0.6$ & $20.2 \pm 5.9$ & $21.8 \pm 0.8$ & $5.6 \pm 0.9$ & $11.4 \pm 0.7$ \\
\hline 7 & - & $5 \pm 1.4$ & $16.7 \pm 1.4$ & $1.1 \pm 0.4$ & $20.1 \pm 0.6$ & $13.4 \pm 1.7$ & $37.5 \pm 2.5$ \\
\hline 8 & - & $1.8 \pm 0.5$ & $2.7 \pm 0.3$ & $1.3 \pm 0.3$ & $5.7 \pm 0.2$ & $10.8 \pm 2.5$ & $5.6 \pm 0.4$ \\
\hline 9 & - & $13.6 \pm 3.3$ & $68.9 \pm 0.5$ & $10.6 \pm 2.9$ & $44.2 \pm 1.5$ & $33.1 \pm 4.1$ & $21.7 \pm 3.5$ \\
\hline 10 & - & $5.6 \pm 2.0$ & $6.8 \pm 0.7$ & $17.9 \pm 3.5$ & $3.5 \pm 0.3$ & $21.8 \pm 4.2$ & $1.3 \pm 0.2$ \\
\hline 11 & - & - & - & - & - & $5.4 \pm 1.2$ & - \\
\hline 12 & - & - & - & - & - & $8.2 \pm 4.3$ & - \\
\hline sample size & 5 & 5 & 5 & 5 & 5 & 4 & 5 \\
\hline
\end{tabular}

